\title{
Oral bioaccessibility of potentially toxic elements (PTEs) in urban dusts of Abakaliki, Ebonyi State, Nigeria
}

\section{${ }^{* 1}$ NWABUEZE I. ELOM; JANE A. ENTWISTLE; JOHN R. DEAN}

${ }^{\#}$ Department of Applied Sciences, Northumbria University, Newcastle upon Tyne NE1 8ST, UK.

*Department of Geography, Northumbria University, Newcastle upon Tyne NE1 8ST, UK

\section{KEY WORDS: Urban dust, PTEs, oral ingestion, bioaccessibility, ICP-MS, Abakaliki}

\begin{abstract}
A literature survey has shown that no study has investigated the oral bioaccessibility of PTEs in Nigeria dusts. Studies on human health risk of PTEs from urban Nigeria dust have been based only on total elemental concentrations. Whilst this protocol is useful in assessing human health of PTEs, it could lead to an over estimation of the risk considering the elemental sequestration in the dust samples. This study deviated from previous studies by examining the total concentrations as well as the oral bioaccessibility of 8 PTEs in 15 urban dust samples collected from Abakaliki, Ebonyi State, Nigeria. The result showed that high concentrations of $\mathrm{Pb}$ (ranging from $236-1815 \mathrm{mg} / \mathrm{kg}$ ) were observed in 5 locations. The Unified Bioaccessibility Method (UBM) was used to investigate the oral bioaccessibility of these PTEs in the urban dust samples. The result revealed that all the PTEs were more bioaccessible in the gastric phase that the gastric + intestinal phase. The lead tolerable daily intake (TDI), as well as the bioaccessible TDI, was computed and results compared with a guideline value. (C) JASEM
\end{abstract}

\section{http://dx.doi.org/10.4314/jasem.v18 i2.13}

.Introduction: The occurrence and distribution of high concentration of PTEs in urban dusts have been widely reported (Okorie et al., 2012; Xinwei et al., 2009; Al-Khashman, 2007). They sources are also well documented (Wei et al., 2010; Manasreh, 2010). The presence of these PTEs in urban dusts is a potential threat to human health and the ecosystem in general. This is because these elements could enter the human body via the exposure pathways (oral ingestion, inhalation and dermal absorption) (Aelion et al., 2008). In addition, it has been reported that these PTEs have irreversible adverse effects on humans particularly children due to their pica behaviour, physiology, unique exposures and special vulnerabilities (Landrigan et al., 2000). This makes children at a higher risk as their immature organs tend to be more susceptible to PTEs than other contaminants (Egeghy et al., 2011).

A literature survey has shown that only a few authors (e.g. Shinggu et al., 2007; Mashi et al., 2005) have investigated the occurrence of PTEs in Nigerian urban dusts, but none for Abakaliki, Ebonyi State. The survey also showed that all the studies determined only the total elemental concentrations. No study has investigated the bioaccessibility of PTEs in Nigerian dust. It is to be noted that in assessing the human health risk of PTEs, it is not the total concentration of PTEs in urban dust that is of greatest concern but the fraction that is released in the human body (bioaccessible fraction) when dust is ingested. Thus, the use of only total elemental concentration in assessing human health risk of PTEs could be seen as an over estimation of the risk associated with oral ingestion of soil based on the principle of PTEs sequestration within various heterogeneous dust samples; a scenario whereby the total elemental content present in the ingested dust is not readily accessible for absorption and transformation. Hence, there is a need to consider the bioaccessibility of PTEs in urban dust of Abakaliki via in vitro experimental protocols. The oral bioaccessibility is the fraction of the PTEs that are soluble or released from the dust in the human gastrointestinal tract by digestive juices and hence are available for intestinal absorption (Ruby et al., 1999). This protocol has been developed to simulate the dissolution and subsequent absorption of PTEs in the human gastrointestinal tract when dust (soil) is ingested. In this work, the Unified Bioaccessibility Method (UBM) (Wragg et al., 2009) has been used to assess the oral bioaccessibility of 8 selected PTEs i.e. As, Cd, Cr, Cu, Mn, Ni, Pb and Zn (US EPA, 1996) in urban dust of Abakaliki, Ebonyi State, Nigeria with the aim of evaluating the human health risk of ingesting urban dusts.

\section{MATERIALS AND METHODS}

Fifteen street dust samples (Figure 1) were collected from Abakaliki, Ebonyi State, Nigeria on 30th January, 2011. All sampled locations were selected randomly but purposefully with due regard to the (high) volume of traffic and (highly) populated pedestrian areas. Samples were collected using a different dustpan and brush at each site; gloves were 
also worn to avoid cross contamination. Each collected sample was transferred to a self-sealing Kraft bag prior to transport back to the laboratory. The sampling procedure was maintained for all locations to minimise sampling variability and maintain sample integrity. The samples were dried in a drying cabinet at a temperature of $35{ }^{\circ} \mathrm{C}$ for 48 hours. The dust samples were then sieved using a $<$ $125 \mu \mathrm{m}$ nylon sieve to remove unnecessary matter such as small pieces of building material and other debris. The $<125 \mu \mathrm{m}$ dust samples collected after sieving were weighed (their mass recorded) and stored in sealed plastic containers. All procedures were carried out without contact with metal objects / utensils to avoid potential sample crosscontamination.

All chemicals used were certified analytical grade. Their sources as well as that of all instrumentation have been reported elsewhere (Elom et al., 2013).

Preparation of reagents for in vitro extraction test: Laboratory reagents needed for extraction were prepared in four different phases (simulated saliva fluid, simulated gastric fluid, simulated duodenal fluid and simulated bile fluid) (Wragg et al., 2009).

To prepare the simulated saliva fluid, $145 \mathrm{mg}$ of amylase, $50.0 \mathrm{mg}$ mucin and $15.0 \mathrm{mg}$ uric acid was added into a 2L HDPE screw top bottle. Also, 896 $\mathrm{mg}$ of $\mathrm{KCl}, 888 \mathrm{mg} \mathrm{NaH}{ }_{2} \mathrm{PO}_{4}, 200 \mathrm{mg} \mathrm{KSCN}, 570 \mathrm{mg}$ $\mathrm{Na}_{2} \mathrm{SO}_{4}, 298 \mathrm{mg} \mathrm{NaCl}$ and $1.80 \mathrm{~mL}$ of $1.0 \mathrm{M} \mathrm{HCl}$ was added into a $500 \mathrm{~mL}$ volume plastic container and made to the mark with water (inorganic saliva component). To prepare the organic saliva component, $200 \mathrm{mg}$ of urea was added to $500 \mathrm{~mL}$ container and made up to the mark with water. Both container (inorganic and organic phases) were simultaneously poured into the 2 L HDPE screw top container; the solution (simulated saliva fluid) was thoroughly mixed to a homogenous state. The $\mathrm{pH}$ of the simulated saliva fluid was measured and it was at $6.5 \pm 0.5$.

In preparing the simulated gastric fluid, $1000 \mathrm{mg}$ of bovine serum albumin, $3000 \mathrm{mg}$ mucin and $1000 \mathrm{mg}$ pepsin was added into a $2 \mathrm{~L}$ HDPE screw top bottle. Then, $824 \mathrm{mg}$ of $\mathrm{KCl}, 266 \mathrm{mg} \mathrm{Na} \mathrm{H}_{2} \mathrm{PO}_{4}, 400 \mathrm{mg}$ $\mathrm{CaCl}_{2}, 306 \mathrm{mg} \mathrm{NH} \mathrm{Nl}_{4}, 2752 \mathrm{mg} \mathrm{NaCl}$ and $8.30 \mathrm{~mL}$ of $37 \% \mathrm{HCl}$ were added into a $500 \mathrm{~mL}$ volume container and made up to the mark with water (inorganic gastric component). To prepare the organic gastric component; $650 \mathrm{mg}$ glucose, $20.0 \mathrm{mg}$ glucuronic acid, $85.0 \mathrm{mg}$ urea and $330 \mathrm{mg}$ glucosamine hydrochloride was added into a $500 \mathrm{~mL}$ volume container and made up to the mark with water. The inorganic and organic components were simultaneously poured into the 2 L HDPE screw top bottle and the resulting simulated gastric fluid was thoroughly mixed. The $\mathrm{pH}$ was measured and found to be within the range of $0.9-1.0$, also the final $\mathrm{pH}$ of mixed saliva $(1 \mathrm{~mL})$ and gastric phase $(1.5 \mathrm{~mL})$ was checked and found to be within specification 1.2 -1.4 .

Simulated duodenal fluid was prepared by first adding $200 \mathrm{mg}$ of $\mathrm{CaCl} 2,100 \mathrm{mg}$ bovine serum albumin, $300 \mathrm{mg}$ pancreatin and $500 \mathrm{mg}$ lipase to a 2 L HDPE screw top container. To prepare the inorganic duodenal components, $564 \mathrm{mg}$ of $\mathrm{KCl}, 80$ mg $\mathrm{KH}_{2} \mathrm{PO}_{4}, 50.0 \mathrm{mg} \mathrm{MgCl}_{2}, 5607 \mathrm{mg} \mathrm{NaHCO}_{3}$, $7012 \mathrm{mg} \mathrm{NaCl}$ and $180 \mu \mathrm{L}$ of $37 \% \mathrm{HCl}$ was added into a $500 \mathrm{~mL}$ volume container and made up to the mark with water. The organic duodenal component was prepared by adding $100 \mathrm{mg}$ urea to $500 \mathrm{~mL}$ volume container and made to the mark with water. Both the inorganic and organic duodenal components were simultaneously poured into the 2 L HDPE screw top bottle, and the simulated duodenal fluid was thoroughly mixed. The $\mathrm{pH}$ was measured and found to be at $7.4 \pm 0.2$

To prepare the simulated bile fluid, $222 \mathrm{mg}$ of $\mathrm{CaCl}_{2}$, $1800 \mathrm{mg}$ bovine serum albumin and $600 \mathrm{mg}$ bile were added to a $2 \mathrm{~L}$ HDPE screw top bottle. The inorganic bile components was prepared by adding $376 \mathrm{mg}$ of $\mathrm{KCl}, 5785 \mathrm{mg} \mathrm{NaHCO}_{3}, 5259 \mathrm{mg} \mathrm{NaCl}$ and $180 \mu \mathrm{L}$ of $37 \% \mathrm{HCl}$ to a $500 \mathrm{~mL}$ volume container and made up to the mark with water. Also the organic bile components was prepared by adding $250 \mathrm{mg}$ urea to $500 \mathrm{~mL}$ volume container and made up to the mark with water. These two separate bile components (inorganic and organic) were poured to the 2 L HDPE screw top bottle and thoroughly mixed. The resulting simulated bile fluid was allowed to stand for one hour at room temperature to ensure complete dissolution of all reagents. The $\mathrm{pH}$ was measured and found to be at $8.0 \pm 0.2$. The final $\mathrm{pH}$ of the mixed saliva $(1.0 \mathrm{~mL})$, gastric $(1.5 \mathrm{~mL})$, duodenal $(3.0 \mathrm{~mL})$ and bile $(1.0 \mathrm{~mL})$ fluid was measured and found to be at $6.3 \pm 0.5$.

Sample preparation using UBM: 'Gastric' Extraction: $0.6 \mathrm{~g}$ of the dust samples, one CRM (BCR 143) was accurately weighed in triplicate and placed into a 50 $\mathrm{mL}$ screw cap sarstedt tube, $9 \mathrm{~mL}$ of simulated saliva fluid was carefully added and the resulting mixture was manually shaken. After 5-15 mins, $13.5 \mathrm{~mL}$ of simulated gastric was added. The extraction vessels were placed in an end-over-end shaker maintained at a temperature of $37 \pm 2{ }^{\circ} \mathrm{C}$ for $1 \mathrm{~h}$. At the end of $1 \mathrm{~h}$, the $\mathrm{pH}$ of each of the soil suspension was measured and were all found to be at the range of $1.2-1.7$. The solutions were collected and centrifuged at $3000 \mathrm{rpm}$ for 5 mins. $1.0 \mathrm{~mL}$ of the supernatant was pipetted into a labelled centrifuge tube and $9.0 \mathrm{~mL}$ of $0.1 \mathrm{M}$ HNO3 was added. The prepared extract was kept at < $4{ }^{0} \mathrm{C}$ prior to the measurement of the bioaccessible PTE content using ICP-MS. 
'Gastric + Intestinal' Extraction: $0.6 \mathrm{~g}$ of the dust samples, one CRM (BCR 143) was accurately weighed in triplicate and placed into a $50 \mathrm{~mL}$ screw cap sarstedt, $9 \mathrm{~mL}$ of simulated saliva fluid was carefully added and the resulting mixture was manually shaken. After $5-15$ mins, $13.5 \mathrm{~mL}$ of simulated gastric was added. The extraction vessels were placed in an end-over-end shaker maintained at a temperature of $37 \pm 2{ }^{0} \mathrm{C}$ for $1 \mathrm{~h}$. At the end of $1 \mathrm{~h}$, the $\mathrm{pH}$ of each of the soil suspension was measured and were all found to be at the range of $1.2-1.7$. Having achieved the required $\mathrm{pH}$ at this stage, 27.0 $\mathrm{mL}$ of simulated duodenal fluid and $9.0 \mathrm{~mL}$ of simulated bile fluid were added to the mixture in the Sarstedt tube, capped and manually shaken to ensure mixing of the components.

The $\mathrm{pH}$ of the resultant suspensions was adjusted to $6.3 \pm 0.5$ with the drop wise addition of $37 \% \mathrm{HCl}, 1$ $\mathrm{M}$ or $10 \mathrm{M} \mathrm{NaOH}$ as required. The extraction tubes were placed in an end-over-end shaker maintained at $37{ }^{\circ} \mathrm{C} \pm 2$ and allowed to shake for $4 \mathrm{~h}$. Then the soil suspensions were removed from the shaker, $\mathrm{pH}$ measured and were found to be at $6.3 \pm 0.5$. These were centrifuged at $300 \mathrm{rpm}$ for $5 \mathrm{mins}, 1.0 \mathrm{~mL}$ of the supernatant was pipetted into a labelled centrifuge tube and $9.0 \mathrm{~mL}$ of $0.1 \mathrm{M} \mathrm{HNO} 3$ was added. The prepared extract was kept in the fridge (at $<4{ }^{0} \mathrm{C}$ ) prior to analysis using ICP-MS.

Microwave digestion protocol: $0.5 \mathrm{~g}$ of each dust sample and CRM were accurately weighed into a 65 mL PFA (a perfluoralkoxy resin) microwave vessel pre-cleaned with concentrated acid. An acid mixture (aqua regia) of $13 \mathrm{~mL}\left(\mathrm{HCl}: \mathrm{HNO}_{3}, 3: 1 \mathrm{v} / \mathrm{v}\right)$ was carefully added into the PFA vessels and sealed with a TFM cover. The solution was gently swirled to homogenize the sample with the reagents; the vessels were then introduced into the safety shield of the rotor body and then placed in the polypropylene rotor of the microwave oven. All the vessels containing samples were properly arranged prior to starting the microwave digestion process. The microwave oven was operated at a temperature of $160^{\circ} \mathrm{C}$, power of 750 watts, extraction time of $40 \mathrm{mins}$ and a ventilation (cooling time) of 30 mins. After cooling, the digested samples were filtered using a whatman filter paper (grade 41 , pore size $20 \mu \mathrm{m}$ ) into $50 \mathrm{~mL}$ volumetric flask. The filtrate was diluted to the mark with ultrapure water of resistivity $18.2 \mathrm{M} \Omega-\mathrm{cm}$ at $25{ }^{\circ} \mathrm{C}$. It was then transferred into a $50 \mathrm{~mL}$ Sarstedt tube and stored in the refrigerator $\left(<4{ }^{0} \mathrm{C}\right)$ prior to PTE content determination using ICP-MS.

Inductively coupled plasma mass spectrometry (ICP$M S)$ protocol: Samples to be analysed by ICP-MS were prepared in triplicate by measuring $1 \mathrm{~mL}$ of either the filtrate, CRM or blank into a $10 \mathrm{~mL}$ Sarstedt tube; this was followed by addition of $30 \mu \mathrm{L}$ of mixed internal standard (Indium (In), Scandium
(Sc) and Terbium (Tb) and $9 \mathrm{~mL}$ of water $(1 \%$ $\mathrm{HNO}_{3}$ ). The use of the CRM was to assess the precision and accuracy of the methodology whilst reagent blanks were included to check contamination. Eight calibration standards over the range 0-400 ppb were prepared from a $100 \mathrm{ppm}$ multi-element standard with the mixed internal standard; this was used to calibrate the instrument and also to construct the calibration curves. The instrument was tuned to verify mass resolution and maximise sensitivity. This was done in both standard mode and Collision Cell Technology (CCT) mode. On that basis ${ }^{75} \mathrm{As},{ }^{52} \mathrm{Cr}$, ${ }^{63} \mathrm{Cu},{ }^{55} \mathrm{Mn},{ }^{60} \mathrm{Ni}$ and ${ }^{66} \mathrm{Zn}$ were determined using $\mathrm{CCT}$ mode whereas ${ }^{111} \mathrm{Cd}$ and ${ }^{208} \mathrm{~Pb}$ were determined using standard mode. During sample analysis, calibration standards were determined after every tenth sample to check for instrument consistency. Calibration curves for PTEs based on a concentration range of $0-400 \mathrm{ppb}$ with 8 calibration data points were done on ICP-MS and the regression coefficient $\left(\mathrm{R}^{2}\right)$ obtained for both modes was 0.999 (linear graph). The detection limit is as follows: As (0.1 $\mu \mathrm{g} / \mathrm{L}), \mathrm{Cd}(0.1 \mu \mathrm{g} / \mathrm{L}), \mathrm{Cr}(0.3 \mu \mathrm{g} / \mathrm{L}), \mathrm{Cu}(0.2 \mu \mathrm{g} / \mathrm{L})$, $\mathrm{Mn}(0.2 \mu \mathrm{g} / \mathrm{L}), \mathrm{Ni}(0.2 \mu \mathrm{g} / \mathrm{L}), \mathrm{Pb}(0.1 \mu \mathrm{g} / \mathrm{L})$ and $\mathrm{Zn}(4$ $\mu \mathrm{g} / \mathrm{L})$.

\section{RESULTS AND DISCUSSION}

To check the quality control of the method employed in this work, a CRM (BCR 143R) was analysed for total elemental concentration as well as oral bioaccessibility. Excellent results were obtained for the total PTE determination compared to certificate values (Table 1), with adequate results for the oral bioaccessible PTE determination (Table 1). The \% accuracy was found to be in the range of $99-101$.

The total concentrations of $\mathrm{As}, \mathrm{Cd}, \mathrm{Cr}, \mathrm{Cu}, \mathrm{Mn}, \mathrm{Ni}$, $\mathrm{Pb}$ and $\mathrm{Zn}$ were determined from the $<125 \mu \mathrm{m}$ particle size fraction. The results indicate that the total concentrations of PTEs in the urban dusts vary from location to location with $\mathrm{Pb}$ giving the highest concentration $(1815 \mathrm{mg} / \mathrm{kg})$ and $\mathrm{Cd}$ the least concentration $(0.288 \mathrm{mg} / \mathrm{kg})$. Cadmium was not detected in two locations. The range of mean total PTE concentrations was found in this order: $3.59-$ $15.3 \mathrm{mg} / \mathrm{kg}$ (As); $66.8-172 \mathrm{mg} / \mathrm{kg}$ (Cd); $0.288-1.36$ $\mathrm{mg} / \mathrm{kg}(\mathrm{Cr}) ; 25.4-86.6 \mathrm{mg} / \mathrm{kg}(\mathrm{Cu}) ; 55.5-1815$ $\mathrm{mg} / \mathrm{kg}(\mathrm{Pb}) ; 397$ - $1389 \mathrm{mg} / \mathrm{kg}(\mathrm{Mn}) ; 22.3$ - 52.7 $\mathrm{mg} / \mathrm{kg}(\mathrm{Ni})$ and $73.3-434 \mathrm{mg} / \mathrm{kg}(\mathrm{Zn})$. A box plot (Figure 2) showing median, mean, box boundary (25th and 75th percentile) and whiskers (10th and 95th percentile) has been used to show the distribution of these PTEs.

One way to access health risk of oral ingestion of dust especially by children is to compare the total PTE concentrations with soil guideline values (SGVs). As at the time of this work none exist for Nigeria and none internationally. Therefore, it was considered necessary to compare the result obtained 
in this work with South African SGVs (the only country in the African continent with SGVs). The South African SGVs for a standard residential land scenario are as follows: As (48 mg/kg); Cd (32 $\mathrm{mg} / \mathrm{kg}) ; \mathrm{Cr}$ (9600 mg/kg); Cu (2300 mg/kg); Mn (1500 mg/kg); Ni (1200 mg/kg); Pb (230 mg/kg); and, Zn (1900 mg/kg) (FWMCL, 2010). It can be seen that all the PTEs are below the South African SGVs across the locations, except $\mathrm{Pb}$, which was found to exceed the SGVs in five locations: Outside of Trinity Methodist Church $(236 \mathrm{mg} / \mathrm{kg})$; Outside of Abakpa market (338 mg/kg); Abacha roundabout (1815 $\mathrm{mg} / \mathrm{kg})$; Vanco roundabout $(925 \mathrm{mg} / \mathrm{kg})$ and Ogoja road roundabout by United Bank for Africa (318 $\mathrm{mg} / \mathrm{kg}$ ). Based on these findings, there is a need for further investigation of the risk via an oral bioaccessibility protocol.

The bioaccessibility results showed that the PTEs were more bioaccessible in the gastric phase (stage I) than in the gastric intestinal stage (stage II). The range of $\% \mathrm{BAF}$ (gastric phase) across the 15 locations was as follows: $35.7-51.9(\mathrm{As}) ; 39.4-$ $46.0(\mathrm{Cd}) ; 40.6-66.9(\mathrm{Cr}) ; 36.4-52.6(\mathrm{Cu}) ; 24.5-$ $51.5(\mathrm{~Pb}) ; 35.8-56.8(\mathrm{Mn}) ; 40.550 .8(\mathrm{Ni})$ and 32.6 $-51.3(\mathrm{Zn})$. On the other hand, the range of $\% \mathrm{BAF}$ (gastric + intestinal phase) are as follows: $27.8-41.4$ (As); $30.9-41.1$ (Cd); 25.9 - $37.6(\mathrm{Cr}) ; 31.4-39.6$ $(\mathrm{Cu}) ; 29.1-39.6(\mathrm{Mn}) ; 29.2-39.5(\mathrm{Ni}) ; 28.9-41.7$ $(\mathrm{Pb})$ and $27.4-39.3(\mathrm{Zn})$. It can be seen that the \% BAF varied across the elements. However, this study did not investigate the different forms in which these elements occurred in the urban dust; the differences in their bioaccessibility suggest that these elements may occur in different chemical forms. The higher \% $\mathrm{BAF}$ in the gastric phase is expected because the solubilisation of these PTEs is higher in the more acidic environment (gastric phase) than in the higher $\mathrm{pH}$ medium (intestinal phase) where re-adsorption and precipitation occurs (Roussel et al., 2010). It is observed that \% BAF in both stages is less than $100 \%$. This justifies the significance of bioaccessibility studies when assessing human health risk of oral ingestion of dust and soil with respect to PTEs. The traditional method of using mean total concentration could lead to over estimation of risk taken into consideration the fact that these PTEs occur in various geochemical forms (particulateassociated, exchangeable, carbonate associated, $\mathrm{Fe}$ $\mathrm{Mn}$ associated, hydroxides and residual) (Dean, 2007).

Considering the high $\mathrm{Pb}$ content observed in 5 locations and to further assess the human health risk associated with exposure to urban dust, $\mathrm{Pb}$ total daily intake (TDI), its bioaccessible TDI (gastric only), and the amount of dust that could be consumed by a child ( $3-6$ years) in order to exceed the recommended TDI for soil and dust ingestion of $50 \mathrm{mg} /$ day (US EPA, 2008) were calculated. The guideline $\mathrm{TDI}_{\text {oral }}$ for $\mathrm{Pb}$ is $3.6 \mu \mathrm{g} \mathrm{kg}_{\mathrm{bw}}{ }^{-1} \mathrm{day}^{-1}$ (Baars et al., 2001). Details of the calculations have been reported elsewhere by the authors (Elom et al., 2013). The results obtained are as follows: $4.88 \mu \mathrm{g} \mathrm{kg}_{\mathrm{bw}}{ }^{-1} \mathrm{day}^{-1}\left(\mathrm{TDI}_{\text {oral }}\right) ; 2.54 \mu \mathrm{g}$ $\mathrm{kg}_{\mathrm{bw}}{ }^{-1} \mathrm{day}^{-1}$ (bioaccessible TDI) with $36.9 \mathrm{mg} / \mathrm{kg}$ (the amount of dust that could be consumed by a child to exceed the guideline value). It can be seen that the TDI exceeded the guideline and the amount of dust that could be consumed by a child lower that US EPA guideline of $50 \mathrm{mg} / \mathrm{kg}$ per day (US EPA, 2008). These results suggest the existence of risk in those locations but for the bioaccessible TDI which is lower that the guideline.

Conclusion: The study has demonstrated that the long outstanding approach of using total elemental concentration to assess human health of PTEs from urban dust could lead to an over estimation of the since it has been reported that these PTEs occur in different geochemical forms (Dean, 2007). Although high concentration of $\mathrm{Pb}$ was recorded in 5 locations, the bioaccessibility results (\% BAF and bioaccessible tolerable daily intake (TDI) has shown that no risk exist in those locations. However, it not advisable to expose children to urban dust particularly in those sites were high $\mathrm{Pb}$ content was obtained.

Acknowledgements: The authors are grateful to Ebonyi State University Abakaliki / Education Trust Fund, Nigeria for awarding a studentship to one of us (NIE). We appreciation Mr. Gary Askwith for his assistance in analysing the samples using ICP-MS.

Table 1: Certified value, total concentration, stage related bioaccessible and residual fractions of PTEs in BCR 143R

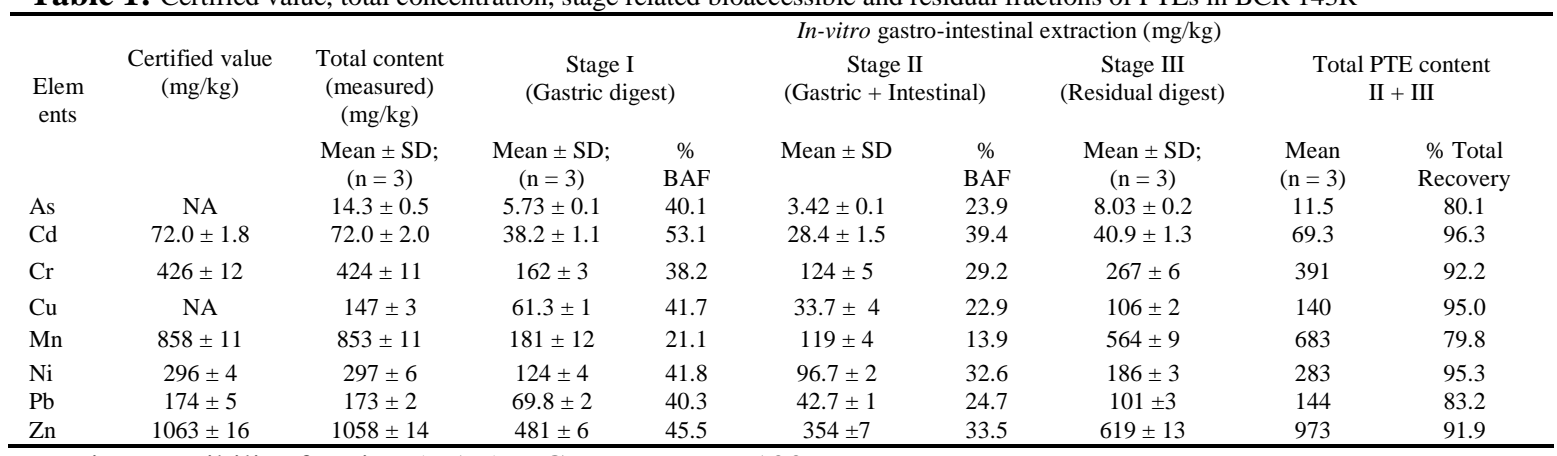

$\%$ Bioaccessibility fraction $(\mathrm{BAF})=\underline{\mathrm{C}}_{\text {Bioaccessibility }} \times 100$ 
$\mathrm{C}_{\text {total content }}$

Where $\mathrm{C}_{\text {Bioaccessibility }}$ is the PTE concentration $(\mathrm{mg} / \mathrm{kg})$ in urban dust samples obtained via the application of the UBM and $\mathrm{C}_{\text {total content }}$ is the PTE total content $(\mathrm{mg} / \mathrm{kg})$ in urban dust samples obtained via the microwave digestion protocol.

$\%$ Total Recovery: total recovery fraction calculated as a fraction of the total concentration; NA: not available.

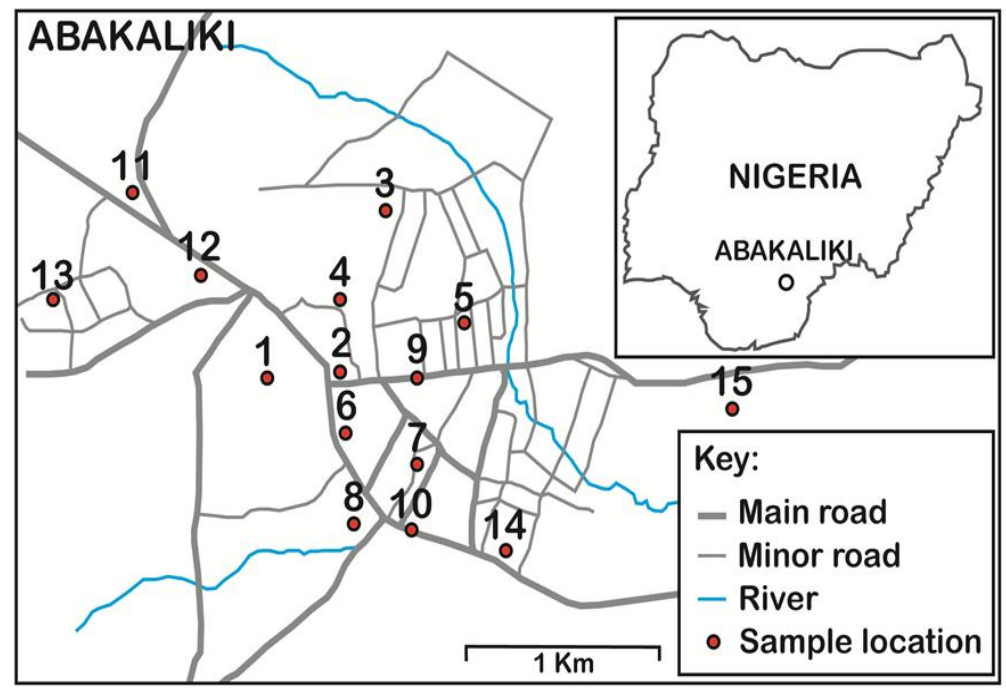

Fig 1: Identification of the fifteen sampling locations in Abakaliki

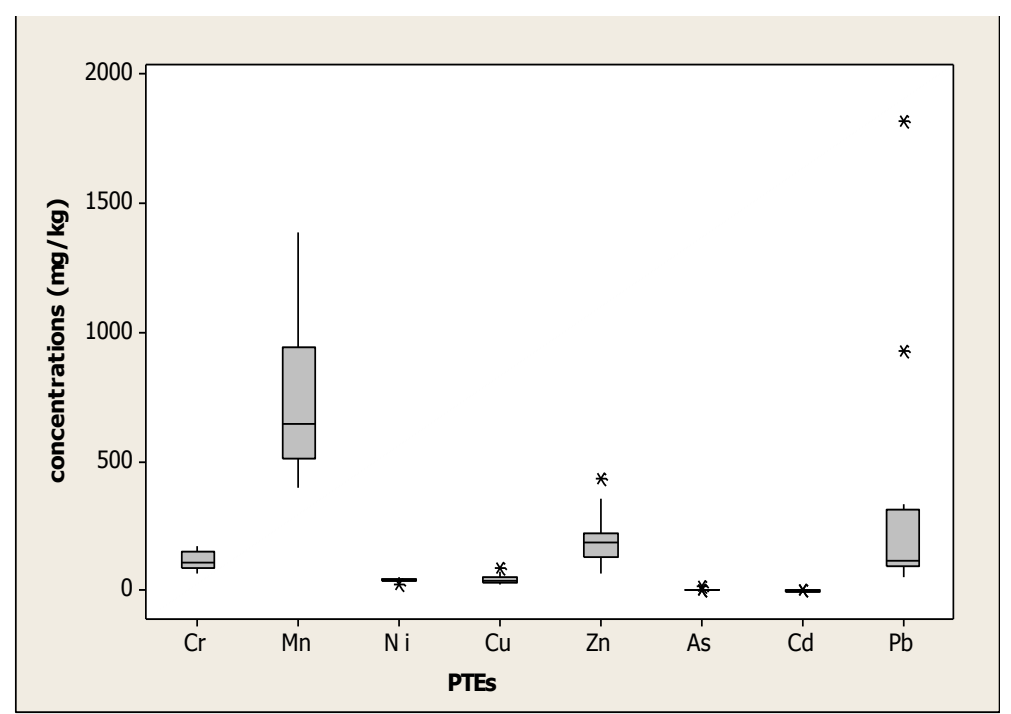

Fig 2: A box plot showing PTEs concentration in urban dust

\section{REFERNCES}

Aelion, C., Davies, H., McDermott, S., Lawson, A. (2008). Metal contamination in rural topsoil in South Carolina: potential for human health impact. Science of the Total Environment, 402, $149-156$.

Al-Khashman, O.A. (2007).The investigation of metal concentrations of street dust samples in Aqaba city, Jordan. Environmental Geochemistry and Health, 29, 197-207.

Baars, A.J., Theelen, R.M.C., Janssen, P.J.C.M., Heese, J.M., Van Apeldoorn, M.E., Meijerink,
M.C.M., Verdam, L., Zeilmaker, P.J.C.M. (2001). Re-evaluation of human toxicological maximum permissible risk levels. National Institute of Public Health and the Environment (RIVM). Report 711701025.

Dean, J.R., (2007). Bioavailability, bioaccessibility and mobility of environmental contaminants. John Wiley \& sons, Ltd, UK.

Egeghy, P.P., Hubal, E.A.C., Tulve, N.S., Melnyk, L.J., Morgan, M.K., Fortmann, R.C., Sheldon, L.S. (2011). Review of pesticides urinary biomarker measurements from selected US EPA 
children's observational exposure studies. International Journal of Environmental Research and Public Health, 8, 1727 - 1754.

Elom, N.I., Entwistle, J.A., Dean, J.R. (2013). How safe is the playground? An environmental health risk assessment of $\mathrm{As}$ and $\mathrm{Pb}$ levels in playing fields in NE England. Environmental Chemistry letters. DOI 10.1007/s10311-013-0413-7.

Frame Work for the Management of Contaminated Land (FWMCL) (2010). Environmental Affairs; Republic of South Africa.

http://www.environment.gov.za/ (accessed on June, 2012).

Landrigan, P.J., Kimmel, C.A., Correa, A., Eskenazi, B. (2000). Children's health and the Environment: Public Health Issues and challenges. Environmental Health Perspectives, $112,257-265$.

Manasreh, W.A. (2010). Assessment of trace metals in street dust of Mutah city, Karak, Jordan. Carpathian Journal of Earth and Environmental Science, 5, 5-12.

Mashi, S.A., Yaro, S.A., Eyong, P.N. (2005). A survey of trends related to the contamination of street dust by heavy metals in Gwagwlada, Nigeria. Management of Environmental Quality: An International Journal, 16 (1), 71 - 76.

Okorie, A., Entwistle J.A., Dean J.R. (2012). Estimation of daily intake of potentially toxic elements from urban street dust and the role of oral bioaccessibility testing. Chemosphere, 86, 460-467.

Roussel, H., Waterlot, C., Pelfrene, Pruvot, C.,Mazzuca, M., Douay, F. (2010). Cd, Pb and $\mathrm{Zn}$ oral bioaccessibility of urban soils contaminated in the past by atmospheric emissions from two lead and smelters. Archives of Environmental Contamination Toxicology, 58, $945-954$
Ruby, M.V., Schoof, R., Brattin, W., Goldade, M., Post, G., Harnois, M., Mosby, D.E., Castle, S.W., Berti, W., Carpenter, M., Edwards, D., Cragin, D., Chappell, W. (1999). Advances in evaluating the oral bioavailability of inorganics in soil for use in human health risk assessment. Environmental Science and Technology, 33, $3697-3705$.

Shinggu, D.Y., Ogugbuaja, V.O., Bariminas, J.T., Toma, I. (2007). Analysis of street dust for heavy metal pollutants in Mubi, Adamawa State, Nigeria. International Journal of Physical Sciences, 2 (11), 290 -293.

US EPA (1996). Soil screening guidance: User's guidance. US Environmental Protection Agency. USEPA, Washington, DC., EPA 54/R-96/018.

US EPA. (2008). Child specific Exposure Factors Handbook (Final Report) 2008. US Environmental Protection Agency, Washington, DC, EPA/600/R-06/096F.

Wei, B., Jiang, F., Li, X., Mu, S. (2010). Contamination levels assessment of potentially toxic metals in road dust deposited in different types of urban environment. Environmental Earth Science, 61, 1187-1196.

Wragg, J., Cave, M., Taylor, H., Basta, N., Brandon, E., Casteel, S., Gron, C., Oomen, A., Van De Wiele, T. (2009). Inter-laboratory trial of Unified Bioaccessibility Procedure. British Geological Survey Open report, OR/07/027.

Xinwei, 1., Lijun, W., Kai, L., Jing H., Yuxiang, Z. (2009). Contamination assessment of copper, lead, manganese and nickel dust of Baoji, china. Hazardous Materials, 161, 1058 -1062. 